\title{
Design of envelope amplifier based on interleaved multiphase buck converter with minimum time control for $R F$ application
}

\author{
Centro de Electrónica Industrial \\ Universidad Politécnica de Madrid \\ Madrid, Spain \\ pengming.cheng@upm.es
}

P. M. Cheng, M. Vasić, O. Garcia, J. A. Oliver, P. Alou, J. A. Cobos

\begin{abstract}
In this paper, an interleaved multiphase buck converter with minimum time control strategy for envelope amplifiers in high efficiency RF power amplifiers is proposed. The solution for the envelope amplifier is to combine the proposed converter with a linear regulator in series. High efficiency of envelope amplifier can be obtained through modulating the supply voltage of the linear regulator. Instead of tracking the envelope, the buck converter has discrete output voltage that corresponding to particular duty cycles which achieve total ripple cancellation. The transient model for minimum time control is explained, and the calculation of transient times that are pre-calculated and inserted into a lookup table is presented. The filter design trade-off that limits capability of envelope modulation is also discussed. The experimental results verify the fast voltage transient obtained with a 4-phase buck prototype.
\end{abstract}

\section{INTRODUCTION}

In wireless communication system, RF power amplifiers (RFPA) have significant power consumption. In order to have high linearity, Class- $A$ and Class-AB mode are usually used in RFPA. However, these amplifiers have low power efficiency with operation point at less than the maximum output power. If the amplified signals have high peak to average power ratio (PAPR), these amplifiers have very low average efficiency. Unfortunately, a lot of wireless standards, like CDMA, WCDMA and LTE, have signals with high PAPR. Therefore, Envelope elimination and restoration (EER) technique has been proposed in order to improve system efficiency by using switching mode RFPA and high efficiency power converter modulating the power supply of RFPA, as it can be seen in Fig. 1. The challenge of high efficiency EER system is to design a high efficiency converter that can track the wide bandwidth signal envelope.

Several solutions for this high efficiency power converter in EER technique have been proposed in the state of art. A three-level buck converter in [1] is for low-power portable device application, which can obtain the effective doubling

This work has been supported by the Ministry of Education and Science of Spain for the project TEC2009-14307-C02-01 of the switching frequency. This solution results in favorable trade offs between switching ripples, switching frequency and the size of the filter. Also, the interleaved multiphase converter in [2] has the same trade-offs. However, these switch-mode converters' limitation is the significant power

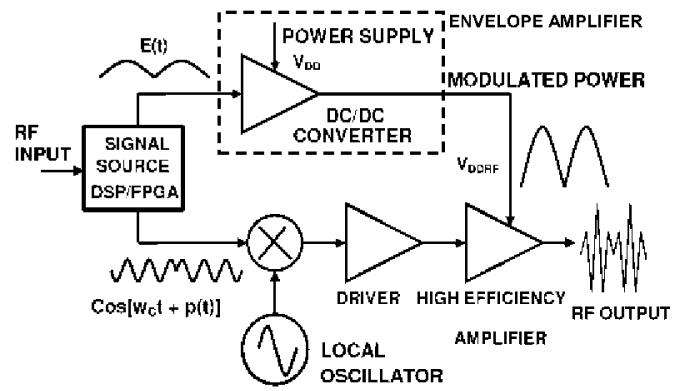

Fig. 1 Simplified block diagram of EER technique

losses in wide-bandwidth envelope application, because the switch frequency has to be several times envelope bandwidth in order to track the envelope, which leads to high switching power losses. To achieve wide bandwidth tracking without pushing switching converter working at extremely high frequency, a switch-mode converter combined with linear regulator is proposed in [3]. In this solution, a multiple input buck converter is in parallel with a linear regulator. When the output of envelope amplifier has high PAPR, the linear regulator will have high power losses, which causes reduced efficiency. Therefore, a multilevel switched-mode converter in series with a linear regulator solution is proposed in [4]. It has discrete output voltages from power converter roughly tracking the envelope and the linear regulator behaves as a low pass filter in order to rebuild the envelope.

A high efficiency envelope amplifier solution which employs a multiphase buck converter in series with a high slew rate linear regulator has been proposed in our previous work [5]. Fig. 2 shows a simplified schematic of the proposed idea. The principle is to modulate the power supply 
voltage of linear regulator according to the envelope reference, like in [4], as it can be seen in Fig. 3. Therefore, the previous work mainly discusses the minimum time control strategy in multiphase buck converter which enables the converter to change output voltage between discrete levels fast enough in order to track envelope. This paper will

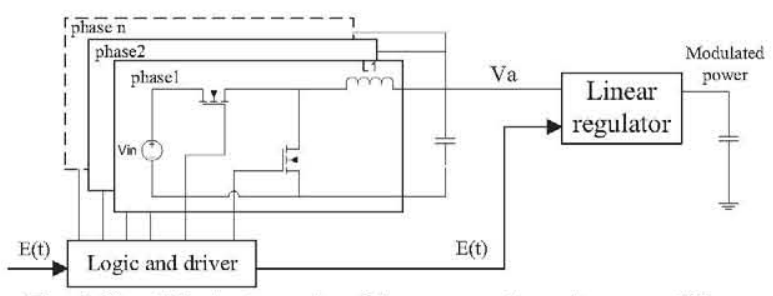

Fig. 2 Simplified schematic of the proposed envelope amplifier

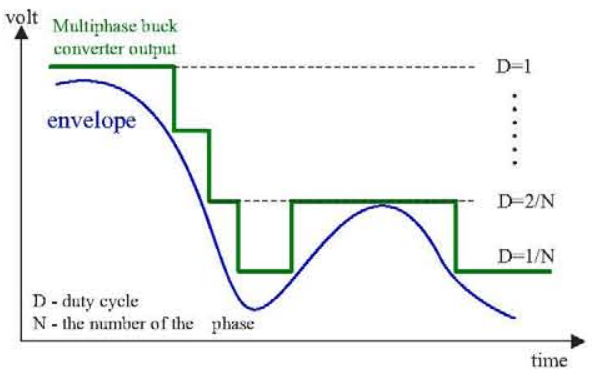

Fig. 3 time diagrams of the envelope amplifier

focus on performance improvement of envelope amplifier, which is based on previous solution.

\section{ENVELOPE AMPLIFIER}

\section{A. Minimum time control methodology applied to multiphase buck converter}

The principle of Minimum Time Control (MTC) is explained in [6-7]. In order to simply the problem, the buck converter is considered as linear system. There are two parameters can be used to describe the state of converter, the inductor current and output voltage. The method of MTC is to change the buck converter from the initial state to the target state through a single on-off switching action [8]. In order to apply MTC properly, some solutions use pre-define on and off time, and the others have control loop to operate MTC. It is necessary to have an accurate converter model in both cases. However, most of work that have been proposed overlook the ripples, but when the minimum time is so small (such as smaller than one switching cycle), the ripples of inductor current can't be neglected.

As aforementioned, the multiphase buck converter has discrete output voltage levels, which means discrete duty cycles. Taking the feature of the interleaved multiphase buck converter into account, the converter can have complete ripple cancellation at several particular duty cycles. Taking advantage of these duty cycles, this paper presents a simple method to pre-calculate the parameters in MTC. Additionally, these duty cycles also give a favorable advantage to output capacitor design, because there is no ripple on the output capacitor. It means small capacitor can be used without suffering from the ripple, which is also demanded by fast output voltage change.

In order to calculate the on and off time during the transition analytically, charge balance method is used. Additionally, there are two assumptions: it is assumed that the output changes linearly during the transition; it is assumed that the load current doesn't change too much if the transition is fast enough. As mentioned in previous paper, during the transition time, the charge balance can be expressed as:

$$
\sum_{\mathrm{i}=1}^{\mathrm{N}} Q_{\mathrm{Li}}=\mathrm{Q}_{\mathrm{C}}+\mathrm{Q}_{\mathrm{LOAD}}=C \cdot \Delta V+\mathrm{Q}_{\mathrm{LOAD}}
$$

Where $\mathrm{Q}_{\mathrm{Li}}$ is the charge provided by each phase of the multiphase converter, $\mathrm{C}$ is the value of the output capacitor, and $\Delta \mathrm{V}$ is the output voltage difference between initial state and target state. With the second assumption, the charge that goes to the load can be:

$$
\mathrm{Q}_{\mathrm{LOAD}}=\mathrm{I}_{\mathrm{LOAD}} \cdot \Delta t
$$

Where $\mathrm{I}_{\text {LOAD }}$ is load current and $\Delta t$ is transition time. And the charge from one phase, $\mathrm{Q}_{\mathrm{Li}}$, can be calculated as:

$$
Q_{L i}=-\frac{V_{i n}}{2 L} t_{O N, i}^{2}-\frac{V_{1}}{2 L} \Delta t^{2}+\frac{V_{i n} t_{O N, i} \Delta t}{L}+I_{i} \Delta t-\frac{\Delta V \Delta t^{2}}{6 L}
$$

Where $I_{i}$ is the $i^{\text {th }}$ indetor's current at the beginning of the transient, $t_{\mathrm{ON}, \mathrm{i}}$ is the interval time when the main switch of the $i^{\text {th }}$ phase is turned on and $\mathrm{L}$ is the value of the inductor in each phase. The equantion for $t_{\mathrm{ON}, \mathrm{i}}$ and $\Delta t$ also can be obtained as:

$$
t_{o n, i}=K \cdot \Delta t+\frac{L \cdot \Delta I_{i}}{V_{i n}}, \quad K=\frac{V_{1}+\frac{V_{2}}{2}}{V_{i n}}
$$

Where $\Delta \mathrm{I}_{\mathrm{i}}$ is the difference of the phase current after and before the transient. With these equations, $\Delta \mathrm{t}$ can be calculated as:

$$
\begin{gathered}
C \Delta V=\Delta t^{2}\left(-\frac{V_{\text {in }}}{2 L} n K^{2}+\frac{V_{\text {in }}}{L} n K-\frac{V_{1}}{2 L} n-\frac{\Delta V}{6 L} n\right) \\
-\frac{L}{2 V_{i n}} \sum_{\mathrm{i}=1}^{\mathrm{N}} \Delta I_{i}^{2}
\end{gathered}
$$

Where $\mathrm{n}$ is the number of the phase. With (4) and (5), the on and off time for each phase can be obtained.

Equation (5) can be used to calculate the step-up transition, not step-down one. In order to calculate the step-down transition time, the charge from each phase, $\mathrm{Q}_{\mathrm{Li}}$. should be:

$$
Q_{L i}=\frac{V_{i n}}{2 L} t_{O N, i}^{2}-\frac{V_{1}}{2 L} \Delta t^{2}+I_{i} \Delta t-\frac{\Delta V \Delta t^{2}}{6 L}
$$


The equantion (4) is the same for step-down. Therefore, the equantion to calculate $\Delta \mathrm{t}$ should be:

$$
C \Delta V=\Delta t^{2}\left(\frac{V_{i n}}{2 L} n K^{2}-\frac{V_{1}}{2 L} n-\frac{\Delta V}{6 L} n\right)+\frac{L}{2 V_{\text {in }}} \sum_{\mathrm{i}=1}^{\mathrm{N}} \Delta I_{i}^{2}
$$

It is important to notice that there is an assumption regarding the load current. It is assumed that the load current doesn't change during the transition. It is true when the envelope changes slowly, but it might include an error when the envelope is fast changing. In order to compensate this error, some modifications can be included in the equation to calculation charge to the load.

From (5) and (7), it can be found that $\Delta \mathrm{I}_{\mathrm{i}}$ has to be known to calculate $\Delta t$. However, if the transient (or the MTC) is synchronized with PWM duty cycle, $\Delta \mathrm{I}_{\mathrm{i}}$ can be calculated through input voltage, duty cycle, inductance and information about the phase shifting. One of the synchronizing ways is to start the transient at the end of PWM cycle of one phase (rising or falling edge). At this moment, all the phases enter the minimum time control and each phase will have different on-time and off-time, but the same transition time. Then the minimum time control ends at the beginning of PWM cycle of that phase (rising or falling edge) and keep the corresponding phase delay for the rest phases, shown in Fig. 4. Therefore, $\Delta \mathrm{I}_{\mathrm{i}}$ for each phase can be exactly calculated. Additionally, the factor that affects the

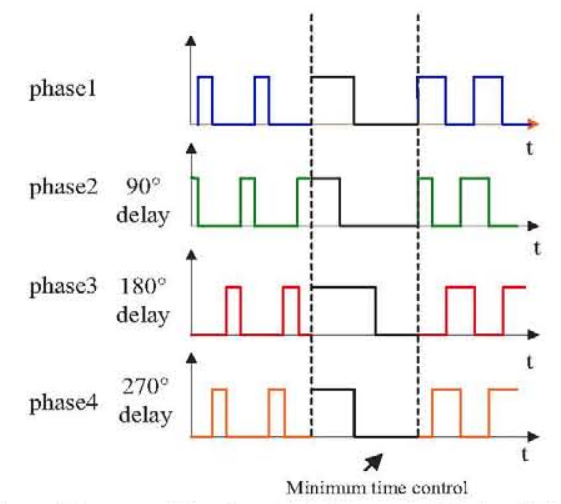

Fig. 4 Control for transition from $0.25 \mathrm{~V}_{\text {in }}$ to $0.5 \mathrm{~V}_{\mathrm{m}}$ in all the phases

transient time will be the sum of the inductor current difference of each phase, not the current of each phase itself, which indicates that a good inductor currents balance is not necessary in this model. And also another important conclusion that can be obtained from these equations is that the MTC calculation doesn't depend on the load current value, which is important for open loop and pre-calculation method.

\section{B. Filter design constrain}

The inductor limits the slew rate of current through the output capacitor, and the output capacitance value determines the charge that has to be delivered during the transient time to change the output voltage. Therefore the output filer (L, C) limits the response time of the buck converter to change the output voltage. And this transient time restrict the maximum bandwidth of the envelope that the converter can modulate. The transient time that the converter needs to change from one state to another one can be calculated through filter parameters. However, the design way is usually inversed. The maximum transient time of the converter that can be accepted is fixed by application (such as the specifications of the transmitted signal). For the given maximum signal slope, there are a plenty of possibilities for the filter parameters $(\mathrm{L}, \mathrm{C})$. Fig. 6 shows the constraint of the filter to track the envelope that has slope lower than 50 volts/us. The combinations of $\mathrm{L}, \mathrm{C}$ and $\mathrm{f}_{\mathrm{Sw}}$ on the surface are the minimum requirement in order to track that envelope. The switching frequency, fsw is used to calculate the current ripple in order to obtain $\Delta \mathrm{I}_{\mathrm{i}}$ in the equations. Additionally, to design for very fast output voltage transient, a high ratio between $\mathrm{L}$ and $\mathrm{C}$ is suitable for charging output capacitor very fast. And it makes inductor size large. On the other hand, the good regulation under the load current change requires a low ratio between $\mathrm{L}$ and $\mathrm{C}$. It reduces the size of inductor, but increases the inductor current ripple and output voltage ripple. Therefore, the transient speed and regulation tradeoff is necessary for a specific design.

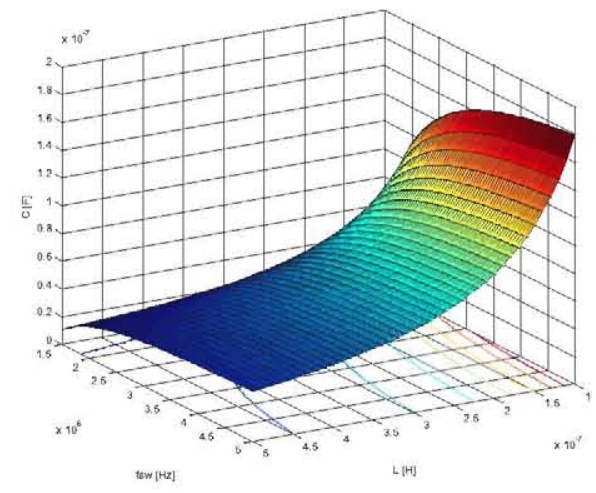

Fig. 5 a constraint of the filter design from output $3 \mathrm{~V}$ to $9 \mathrm{~V}$

\section{Linear regulator}

As aforementioned, a linear regulator is used in series with the multiphase buck converter in the envelope amplifier, seen in Fig. 6.

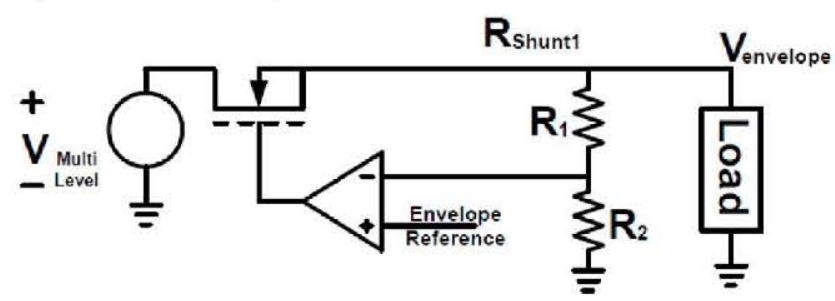

Fig. 6 Simplified schematic of linear regulator in envelope amplifier

The bandwidth of the envelope amplifier is limited by the bandwidth of the linear regulator. Therefore, the MOSFET, operational amplifier and components that operate at high speed should be chosen for this linear regulator. In 
order to obtain a wide bandwidth, the MOSFET's input capacitance should be as low as possible. Also the input capacitor is a part of output capacitor for multiphase buck converter. If it's comparable with the output capacitor, it has to be taken into account in the calculation of MTC.

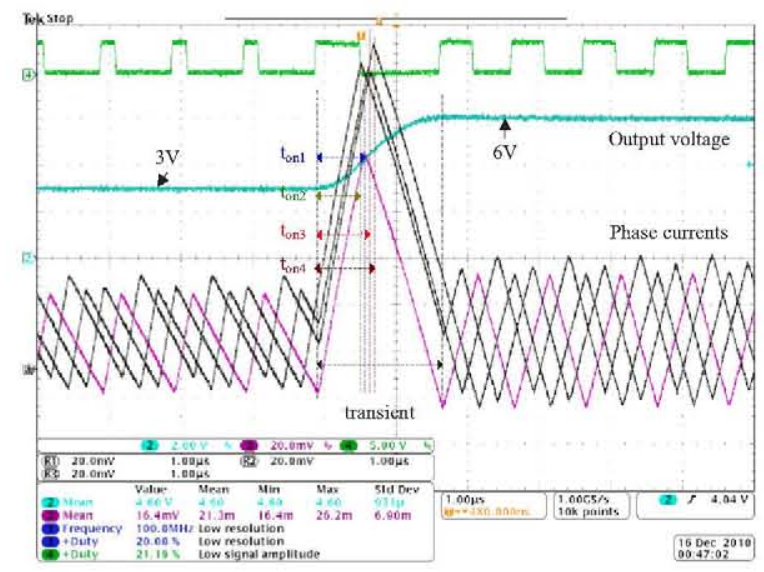

(a) Output voltage step from $3 \mathrm{~V}$ to $6 \mathrm{~V}, 1 \mathrm{MHz}(2 \mathrm{~V} /$ div) and Phase currents $(200 \mathrm{~mA} / \mathrm{div}), \mathrm{L}=6.8 \mathrm{uH}, \mathrm{C}=1 \mathrm{uF}$

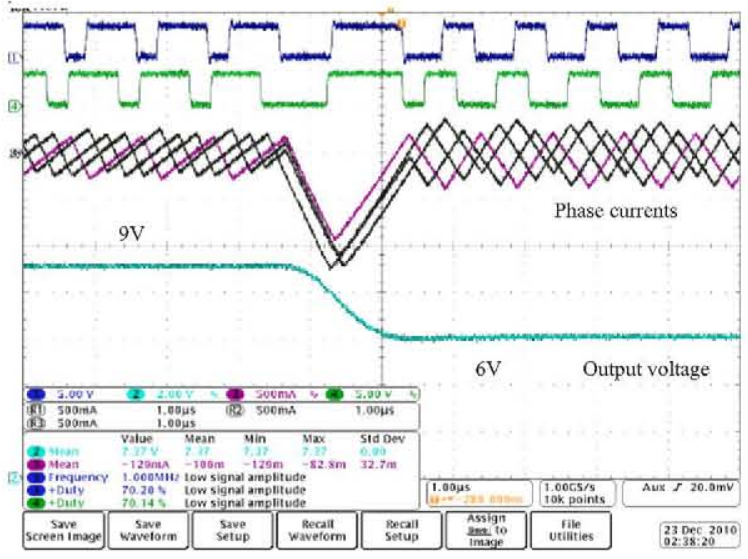

(c) Output voltage step from $9 \mathrm{~V}$ to $6 \mathrm{~V}, 1 \mathrm{MHz}(2 \mathrm{~V} /$ div $)$ and Phase currents $(200 \mathrm{~mA} / \mathrm{div}), \mathrm{L}=6.8 \mathrm{uH}, \mathrm{C}=1 \mathrm{uF}$

\section{EXPERIMENTAL RESULTS}

The design and control methodology are validated with a four phases buck prototype. Fig. 7 shows the comparison of the step-up and step-down with different output filters, which has the output change from $3 \mathrm{~V}$ to $6 \mathrm{~V}(25 \%$ duty cycle to $50 \%)$ and from $9 \mathrm{~V}$ to $6 \mathrm{~V}(75 \%$ duty cycle to $50 \%)$. The

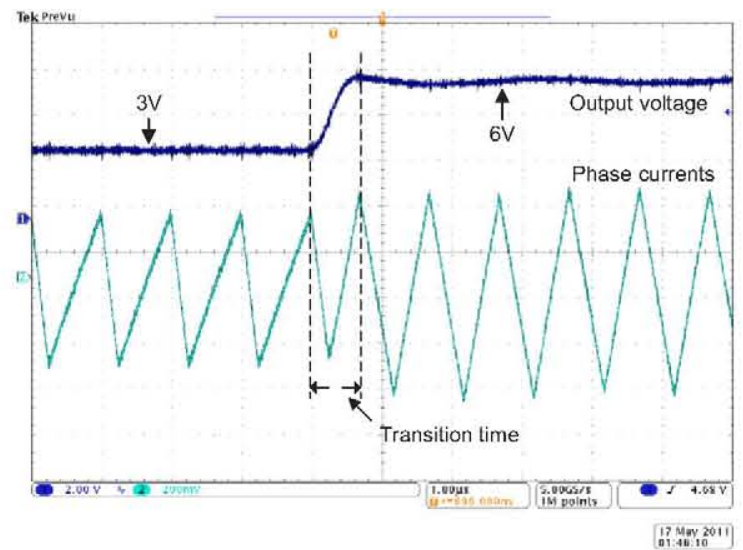

(b) Output voltage step from $3 \mathrm{~V}$ to $6 \mathrm{~V}, 1 \mathrm{MHz}(2 \mathrm{~V} /$ div) and Phase currents $(200 \mathrm{~mA} / \mathrm{div}), \mathrm{L}=4.5 \mathrm{uH}, \mathrm{C}=220 \mathrm{nF}$

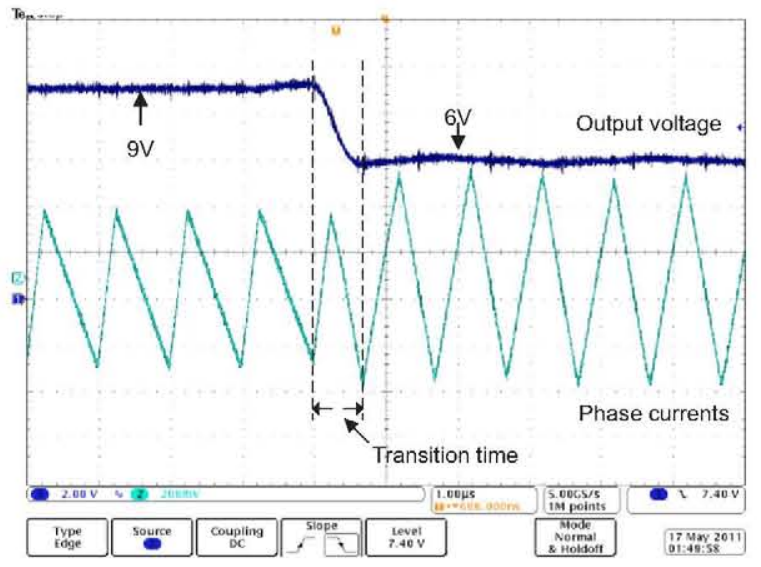

(d) Output voltage step from $9 \mathrm{~V}$ to $6 \mathrm{~V}, 1 \mathrm{MHz}(2 \mathrm{~V} / \mathrm{div})$ and Phase currents $(200 \mathrm{~mA} /$ div) $, \mathrm{L}=4.5 \mathrm{uH}, \mathrm{C}=220 \mathrm{nF}$

Fig. 7 Comparison of transition time between different filter

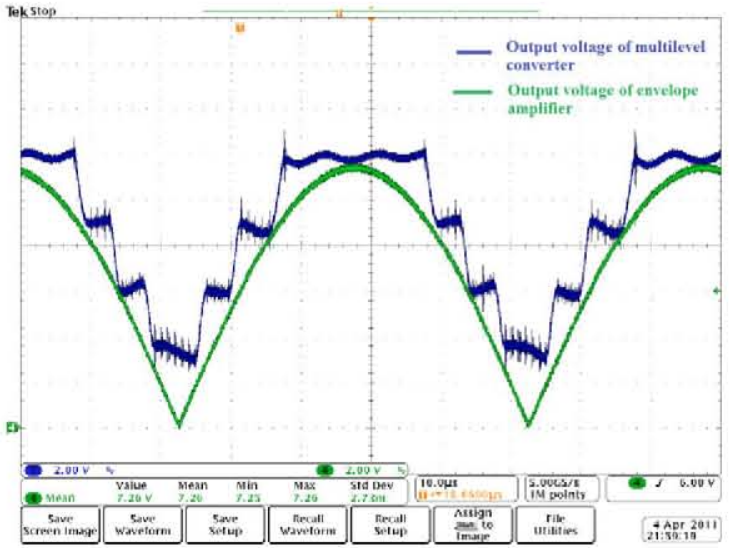

Fig. 8 Output voltage of multilevel converter and envelope amplifier with $20 \mathrm{kHz}$ reference ( $2 \mathrm{~V} / \mathrm{div})$

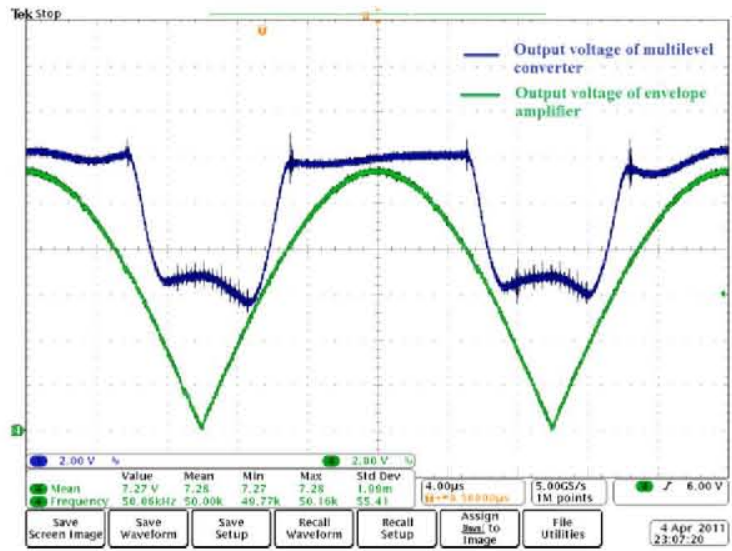

Fig. 9 Output voltage of multilevel converter and envelope amplifier with $50 \mathrm{kHz}$ reference $(2 \mathrm{~V} / \mathrm{div})$ 
input voltage is $12 \mathrm{~V}$ and switching frequency is $1 \mathrm{MHz}$. The one with filter, $\mathrm{L}=6.8 \mathrm{uH}, \mathrm{C}=1 \mathrm{uF}$, has $1.7 \mathrm{us}$ and $1.4 \mathrm{us}$ transition time from $3 \mathrm{~V}$ to $6 \mathrm{~V}$ and from $9 \mathrm{~V}$ to $6 \mathrm{~V}$ respectively and the one with filter, $\mathrm{L}=4.5 \mathrm{uH}, \mathrm{C}=220 \mathrm{nF}$, has 0.65 us and 0.58 us respectively. In this envelope amplifiers application, the load of the buck converter is a linear regulator, which behaves as a current source.

Fig. 8 shows the performance of the implemented interleaved multiphase buck converter in envelope tracking. The envelope reference is a $20 \mathrm{kHz}$ sinusoidal waveform and the discrete output voltage level can be $3 \mathrm{~V}, 6 \mathrm{~V}, 9 \mathrm{~V}$ and $12 \mathrm{~V}$. The measured envelope amplifier efficiency is up to $80 \%$. Fig. 9 shows the envelope amplifier performance with $50 \mathrm{kHz}$ reference. It can be seen that there are only two output voltage level in order to track the envelope, because it is not fast enough to apply all the levels. This shows the flexibility is also an advantage in this application, because it helps the converter to track high slew rate change envelope with relatively low switching frequency. And the system efficiency (envelope amplifier) measured is $76.5 \%$. Both measurements use 10 ohms resistor as the load.

Fig. 10 shows the performance of envelope amplifier with $400 \mathrm{kHz}$ 64QAM envelope reference. The average output power is around $2 \mathrm{~W}$ and the peak output power is $12.1 \mathrm{~W}$. The oscillation of the multiphase buck converter output voltage is obvious, which is at resonant frequency of the output filter. This is inherent drawback of MTC in this application. However, through increasing the margin between supply voltage and the output voltage of linear

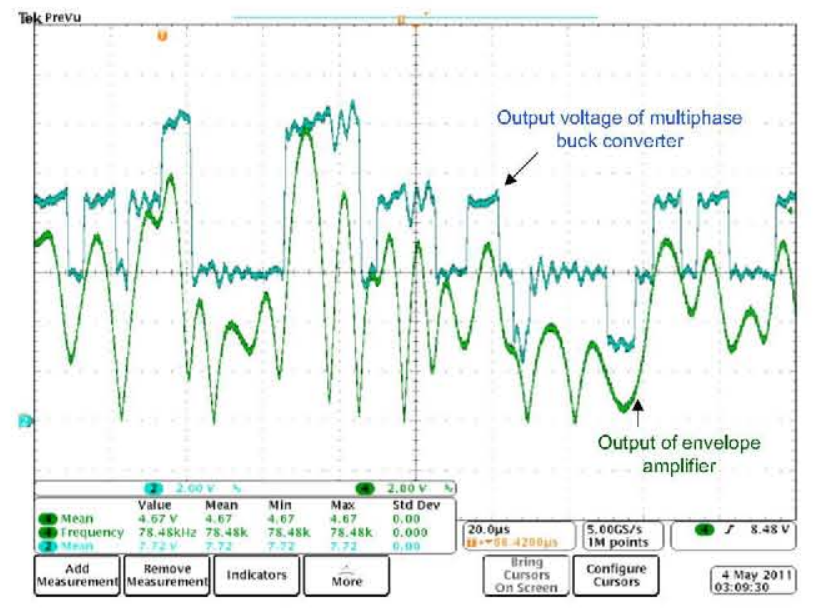

Fig. 10 The envelope amplifier performance with 64QAM

Table. 1 Comparison of interval time from $0.25 \mathrm{Vin}$ to $0.5 \mathrm{Vin}$

\begin{tabular}{|c|c|c|c|c|c|c|c|c|}
\hline \multirow{3}{*}{ phase } & \multicolumn{4}{|c|}{$\mathrm{L}=6.8 \mathrm{uH} \mathrm{C}=1 \mathrm{uF}$} & \multicolumn{4}{|c|}{$\mathrm{L}=4.5 \mathrm{uH} \mathrm{C}=220 \mathrm{nF}$} \\
\hline & \multicolumn{2}{|c|}{ calculation } & \multicolumn{2}{|c|}{ experiment } & \multicolumn{2}{|c|}{ calculation } & \multicolumn{2}{|c|}{ experiment } \\
\hline & $\begin{array}{c}\mathrm{t}_{\mathrm{ON}} \\
\text { [us] }\end{array}$ & $\begin{array}{l}\text { toFF } \\
\text { [us] }\end{array}$ & $\begin{array}{l}t_{\mathrm{ON}} \\
\text { [us] }\end{array}$ & $\begin{array}{l}\text { toFF }_{\text {of }} \\
\text { [us] }\end{array}$ & $\begin{array}{c}t_{\mathrm{ON}} \\
{[\mathrm{ns}]}\end{array}$ & $\begin{array}{l}t_{\mathrm{OFF}} \\
{[\mathrm{ns}]}\end{array}$ & $\begin{array}{l}t_{\mathrm{ON}} \\
{[\mathrm{ns}]}\end{array}$ & $\begin{array}{l}t_{\text {OFF }} \\
{[n s]}\end{array}$ \\
\hline $1^{\text {st }}$ & 2.5 & 5.02 & 2.5 & 4.18 & 230 & 467 & 210 & 470 \\
\hline $2^{\text {nd }}$ & 1.88 & 5.64 & 1.82 & 4.86 & 168 & 529 & 150 & 530 \\
\hline $3^{\text {rd }}$ & 3.76 & 3.76 & 3.98 & 2.7 & 355 & 342 & 340 & 340 \\
\hline $4^{\text {th }}$ & 3.13 & 4.39 & 3.15 & 3.53 & 293 & 404 & 270 & 410 \\
\hline
\end{tabular}

regulator, it can avoid the effect of the oscillation.

Table 1 shows the comparison of the minimum time control between different filters. The transition is from output voltage $0.25 \mathrm{Vin}$ to $0.5 \mathrm{Vin}$. The smaller filter has shorter transition time, but the experiment results have smaller deviation from the calculation. It is due to the aforementioned assumption that output voltage changes linearly during the transition time, and makes an inherent error. When the transition time is small, the output voltage during the transition is closer to linear one.

\section{CONCLUSIONS}

A solution for implementation of a highly efficient envelope amplifier in EER technique is explained in this paper. An interleaved multiphase buck converter with minimum time control strategy in series with a linear regulator can be a high efficiency solution for EER technique envelope amplifiers. The converter operates in certain discrete duty cycles and the output voltage is varied by applying the minimum time control when it is required. The model of minimum time control is presented and filter design is discussed in order to meet the requirement for the variations of output voltage. And it is important to notice that there is no current measurement required for the minimum time control, which makes the implementation very simple. There is also limitation for this solution: the resolution of control will limit the minimum time control application, especially when the transition time is so small according to the fast changing envelope.

\section{REFERENCES}

[1] V. Yousefzadeh, E. Alarcon, D. Maksimović, "Three-level buck converter for envelope tracking in RF power amplifiers," IEEE Trans. on Power Electronics, Volume:21, Issue: 2, March 2006, Pages:549 552.

[2] A. Soto, J.A. Oliver, J.A. Cobos, J. Cezon, F. Arevalo, "Power supply for a radio transmitter with modulated supply voltage", Applied Power Electronics Conference, APEC '04, Feb. 2004.

[3] P.F.Miaja, M.Rodriguez, A.Rodriguez, J.Sebastian, "A linear assisted DC/DC converter for Envelope Tracking and Envelope Elimination and Restoration applications," Energy Conversion Congress and Exposition (ECCE), 12-16 Sept. 2010.

[4] M. Vasić, O. Garcia, J.A. Oliver, P. Alou, D. Diaz, J.A. Cobos, "Multilevel Power Supply for High Efficiency RF Amplifier", Proc. of the 24th Annual IEEE Applied Power Electronics Conference, APEC ' 09 , February 2009.

[5] P. M. Cheng, M. Vasić, O. Garcia, J.A. Oliver, P. Alou, J.A. Cobos, "Multiphase buck converter with minimum time control strategy for RF envelope modulation," IEEE Applied Power Electronics Conference, APEC '11, March 2011.

[6] A. Soto, P. Alou, J.A Cobos, J. Uceda, "Analysis of the buck converter for Scaling the supply voltage of digital circuits", IEEE Transactions on Power Electronics, Volume 22, 6, November 2007 Page(s): $2432-2440$.

[7] Grant E. Pitel, Philip T. Krein, "Minimum-Time Transient Recovery for DC-DC Converters Using Raster Control Surfaces", IEEE Transactions on Power Electronics, Volume 24, 12, December 2009 Page(s): $2692-2703$.

[8] Jurgen Alico, Aleksandar Prodic, "Multiphase Optimal Response Mixed-Signal Current-Programmed Mode Controller", Applied Power Electronics Conference, APEC, 2010. 